IOS Press

\title{
Sequential extraction of black currant residues produces anthocyanin-rich extracts containing anthocyanin dimers
}

\author{
Karin Juedtz ${ }^{\mathrm{a}}$, Nicola Aberdein ${ }^{\mathrm{b}}$, Derek Stewart ${ }^{\mathrm{a}, \mathrm{b}}$ and Gordon J. McDougall ${ }^{\mathrm{a}, *}$ \\ ${ }^{a}$ Environmental and Biochemical Sciences Group, Enhancing Crop Productivity and Utilisation Theme, The James \\ Hutton Institute, Invergowrie, Dundee, UK \\ ${ }^{\mathrm{b}}$ School of Life Sciences, Heriot Watt University, Edinburgh, UK
}

Received 21 August 2012; accepted 31 October 2012

\begin{abstract}
.
BACKGROUND: Annually, the EU processes $\sim 750000 \mathrm{M}$ tonnes of black currants to juice with a substantial production of waste material. This pomace is currently disposed but could be exploited as a source of polyphenol antioxidants, bioactive components and flavour components.

OBJECTIVE: This study investigates the amount and composition of polyphenol components extractable from black currant residues, with a focus on anthocyanin components.

METHODS: Polyphenol levels in laboratory derived juice, successive water-extracts and methanol-extracts of black currants were compared. Similar extractions were carried out on commercial black currant pomace. Differences in polyphenol composition were examined using liquid chromatography mass spectrometry analysis.

RESULTS: Extracts obtained with methanol after juice removal and water washing had considerably higher anthocyanin content and a higher proportion of anthocyanidin glucosides. The methanol extracts also contained putative C-C linked anthocyanin dimers not previously identified in berries. Similar ethanol extraction of commercial pomace also released an anthocyanin-rich fraction with elevated levels of anthocyanidin glucosides.

CONCLUSIONS: Sequential alcohol extraction of black currant residues produced anthocyanin-rich fractions which contained components that may be tightly bound to the residues. These included putative anthocyanin dimers. Compositional differences in extracts from laboratory residues and commercial pomace may be related to the use of cell-wall-lyzing enzymes during juicing.
\end{abstract}

Keywords: Anthocyanins, black currant, juice, polyphenols, processing, pomace

\section{Abbreviations}

$\mathrm{GAE}=$ gallic acid equivalents

PDA $=$ photo-diode array

\footnotetext{
${ }^{*}$ Corresponding author: G.J. McDougall, Environmental and Biochemical Sciences Group, Enhancing Crop Productivity and Utilisation Theme, The James Hutton Institute, Invergowrie, Dundee, DD2 5DA, UK. Tel.: +44 138256 8782; Fax: +44 844928 5429; E-mail: Gordon.mcdougall@ scri.ac.uk.
} 


\section{Introduction}

Black currants are commercially important mainly for the production of juices and concentrates [1]. Black currants contain high levels of vitamin $\mathrm{C}$ and polyphenol antioxidants and breeding work at the James Hutton Institute has focussed on improving the content of both components in new varieties [2]. Black currants are particularly rich in anthocyanins, which are responsible for the intense colour of their juices [3, 4], but also contain appreciable amounts of hydroxycinnamic acid and flavonol derivatives [5] which influence flavour and palatability [6].

Intake of an $80 \mathrm{~g}$ portion of black currants can provide up to $300 \mathrm{mg}$ anthocyanins $[3,7,8]$ and anthocyanins have been associated with positive effects relevant to cardiovascular disease [9], cancers [10], obesity [11], mental performance [12], visual acuity [13] and glycaemic control [14].

Across the EU, it is estimated that each year over $700000 \mathrm{M}$ tonnes of black currants are processed to juice and other products [15] with a substantial accumulation of waste material (approximately 10-20\% of berry weight). This waste press cake or pomace must be disposed (and is often used for animal feed) but could be a source of natural antioxidants, bioactive components and flavour components [e.g. 16-20]. This study describes laboratory simulations of juice production to investigate the amount and composition of polyphenol components extractable from black currant residues, with a focus on anthocyanin components. The study compares polyphenols in the laboratory derived juice, successive water-extracts and methanol-extracts of black currants to assess extractability and composition and compares findings with polyphenols extractable from industrial black currant pomace.

\section{Results and discussion}

\subsection{Extract composition}

The black currant residue after homogenisation was twice extracted with water. The total phenol content of these two water extracts represented a further $13 \%$ of the total phenol content of the original "juice" fraction (Table 1). The extent of this value could differ depending on the means of juice production (e.g. whether seeds were removed), the varieties used and the year of harvest [e.g. 21]. Subsequent extraction of the residue with methanol released a further $2 \%$ of the total "juice" polyphenol content. Although this represents a small portion of the total polyphenol content, these polyphenol components were not extractable by water and therefore must have been bound with considerable affinity to the residues.

The water extracts had a lower phenol concentration than the "juice" but had similar anthocyanin/phenol ratios suggesting that they had similar polyphenol compositions. However, the methanol extracts were notably enriched (approx. 2 fold) in anthocyanins and had a higher relative antioxidant capacity. The antioxidant capacity of the extracts mirrored the anthocyanin/phenol ratio (results not shown) apart for the juice sample, which had a higher antioxidant capacity, possibly as a result of ascorbic acid content.

Table 1

Phenol and anthocyanin content of black currant and pomace extracts

\begin{tabular}{|c|c|c|c|c|c|}
\hline Extract & Phenol concentration $^{\mathrm{a}}$ & Phenol content ${ }^{\mathrm{b}}$ & Anthocyanin content $\mathrm{c}^{\mathrm{c}}$ & $\mathrm{AC} / \mathrm{P}$ ratio & FRAP $^{d}$ \\
\hline "Juice" & $1802 \pm 9$ & $20341(100)$ & $864 \pm 10$ & 0.48 & $10868 \pm 455$ \\
\hline Water 1 & $555 \pm 5$ & $2006(9.8)$ & $239 \pm 6$ & 0.43 & $8599 \pm 365$ \\
\hline Water 2 & $292 \pm 3$ & $675(3.3)$ & $128 \pm 11$ & 0.44 & $8806 \pm 333$ \\
\hline Methanol 1 & $663 \pm 8$ & $283(1.4)$ & $535 \pm 12$ & 0.82 & $13545 \pm 489$ \\
\hline Methanol 2 & $336 \pm 2$ & $119(0.6)$ & $265 \pm 28$ & 0.79 & $14591 \pm 512$ \\
\hline Pomace Water & - & $102.7 \pm 1.1^{\mathrm{e}}$ & $26.5 \pm 0.3$ & 0.26 & - \\
\hline Pomace Ethanol & - & $104.1 \pm 0.4$ & $79.4 \pm 1.3$ & 0.76 & - \\
\hline
\end{tabular}

Figures in parantheses are $\%$ recovery figures based on the values for the juice being set at $100 \%{ }^{\text {a }}$ - phenol concentration is expressed as $\mu \mathrm{g}$ $\mathrm{GAE} / \mathrm{ml},{ }^{\mathrm{b}}$ - the total phenol content is expressed as $\mu \mathrm{g}$ phenols $/ \mathrm{g}$ FW berries, ${ }^{\mathrm{c}}$ - expressed as $\mu \mathrm{g} / \mathrm{ml}$ cyanidin glucoside equivalents, ${ }^{\mathrm{d}}$ - expressed as $\mu \mathrm{M} .{ }^{\mathrm{e}}$ - expressed as $\mu \mathrm{g}$ GAE/g dry weight pomace. 


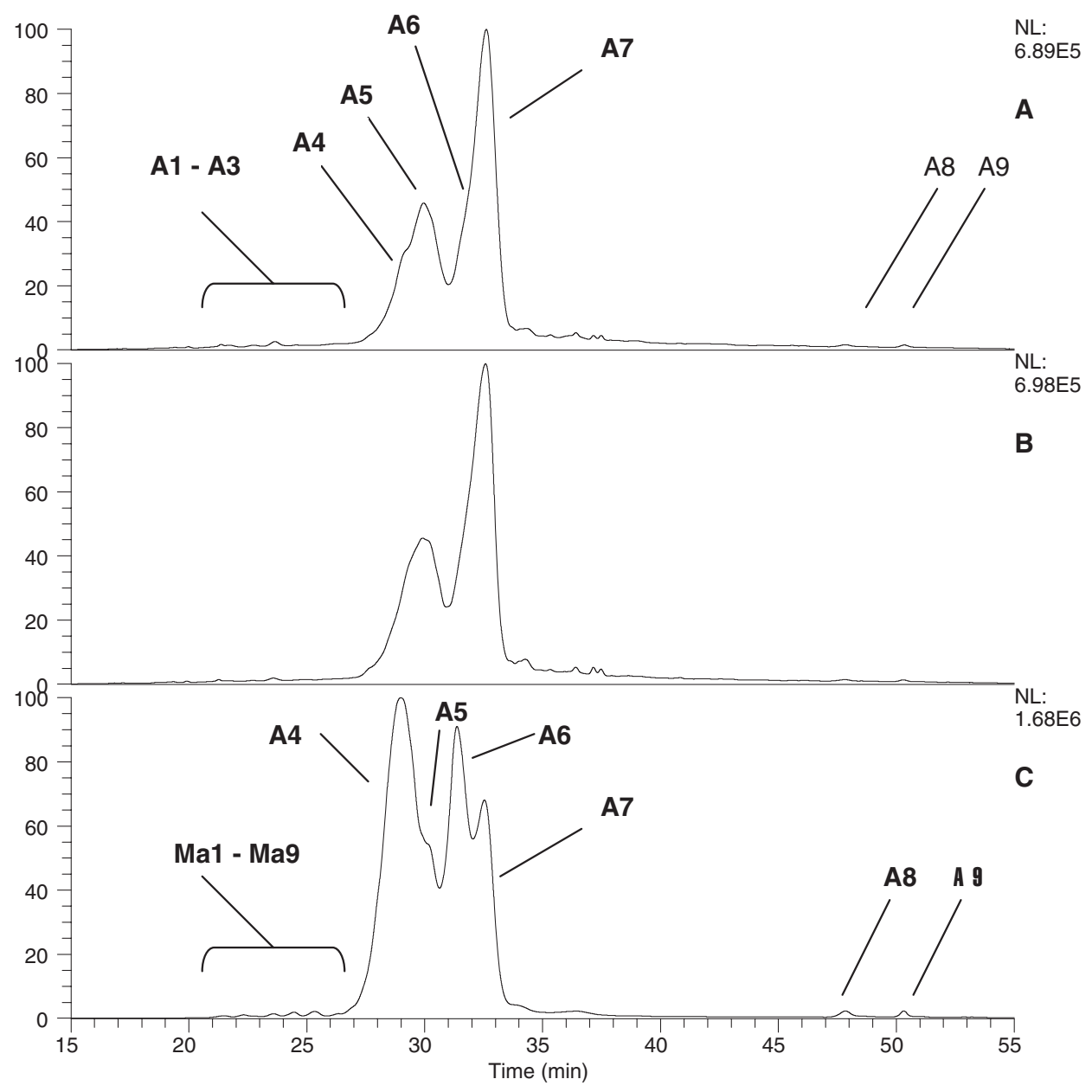

Fig. 1. UV traces of black currant extracts. All traces are recorded at A520. Figures in the top right corners are full scale deflections. A= "juice", $\mathrm{B}=$ water extract $1, \mathrm{C}=$ methanol extract 1 . Peak annotations refer to Table 2 .

The release of anthocyanin-rich extracts from black currant pulp using methanol and/or ethanol after extensive water extraction has been reported previously [22] but the composition of the extracts was not explored. When analysed at equivalent phenol contents, the juice and water extracts gave very similar polyphenol profiles by LC-MS (supplementary data; Supplementary Figure 1). In fact, their polyphenol compositions were similar to previous reports $[6,16,23-28]$ and were dominated by anthocyanins but with sizeable amounts of flavonols and hydroxycinnamate derivatives.

The juice and water extracts gave similar profiles at $520 \mathrm{~nm}$ (Fig. 1b) but the methanol extracts gave an obviously different profile (Fig. 1c). Indeed, it appeared that the methanol extracts had higher levels of the major anthocyanins (glucosides and rutinosides of delphinidin and cyanidin), as assessed by the detector responses. They also had higher levels of the late eluting cyanidin and delphinidin coumaroyl hexoses (Fig. 1c), possibly due to their greater hydrophobicity. Indeed when the levels of the major anthocyanins were estimated by their MS peak areas, there was a notable enrichment in anthocyanidin glucosides (Fig. 2a) in the methanol extracts. A similar pattern was seen in the ethanol extracts of black currant pomace but the enrichment of anthocyanidin glucosides was not so pronounced (Fig. 2b). This differential extractability of anthocyanidin rutinosides over glucosides in water extracts and juices has been noted previously $[6,26]$ and suggests that glucosides are more tightly associated with the berry residues.

Extending these observations to an industrial scale, selection of sequential extraction conditions could yield water extracts which are essentially similar to black currant juice followed by anthocyanin-rich extracts which could find 
a Comparative levels of the major anthocyanins in black currant extracts

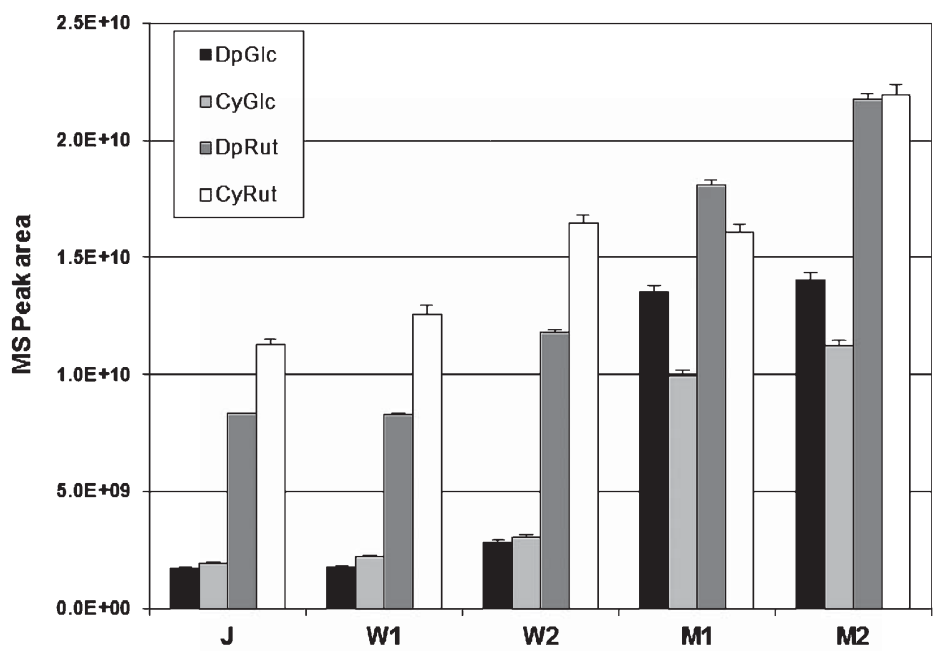

b Comparative levels of the major anthocyanins in black currant pomace extracts

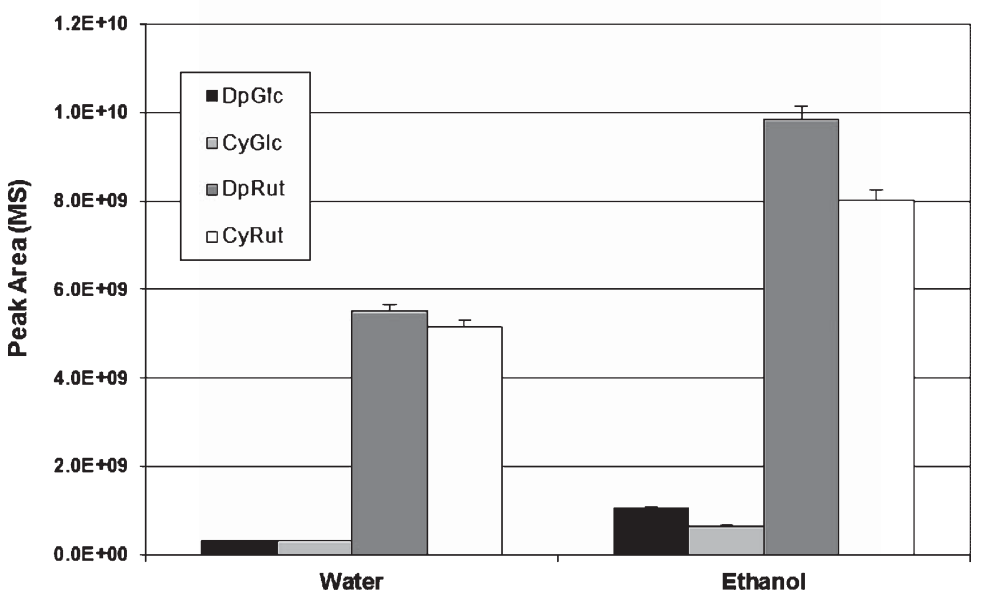

Fig. 2. Comparative content of major anthocyanins in black currant extracts. Figure 2a shows levels of the major anthocyanins from laboratory derived extracts and Fig. $2 \mathrm{~b}$ is the levels from pomace extracts. Peak areas for the $\mathrm{m} / z$ [M+H] value of each anthocyanin component were calculated using $\times$ calibur software. All values are means of triplicate runs \pm standard errors for each component.

use as food-grade colourants or as nutraceutical ingredients [29]. Previous extraction studies on berry pomaces using alcohol-water mixtures $[19,21,30]$ or supercritcal $\mathrm{CO}_{2}$ [e.g. 31, 32] have produced extracts with high antioxidative capacity and often high anthocyanin content. However, they did not examine sequential extractions perhaps because of the increased cost implications of sequential extractions at an industrial level.

After these extractions, the laboratory-derived residues and the pomace still contained substantial "insoluble" antioxidant activity and could be used in foods as an "antioxidant-enriched" source of dietary fibre [33] or as a separate nutraceutical product.

\subsection{Anthocyanin dimers}

A range of early-eluting components were identified in the methanol extracts (Ma1-Ma9) with PDA maxima suggestive of anthocyanin derivatives (Fig. 3A, B, Table 2). Their MS and $\mathrm{MS}^{2}$ properties suggest that they were 


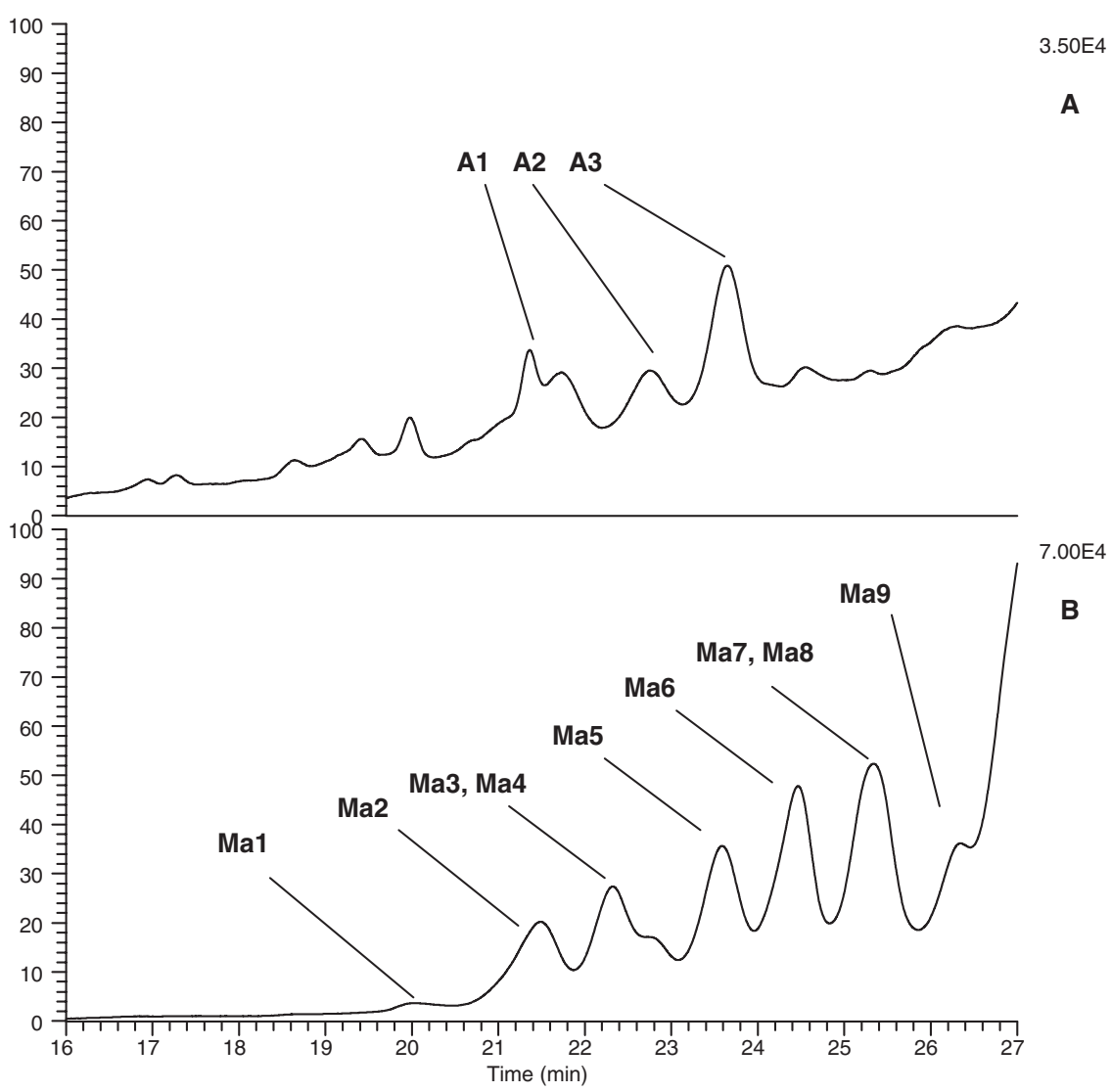

Fig. 3. Early-eluting anthocyanin-like peaks in black currant extracts. All traces are at A520. Figures in the top right corners are full scale deflections. $\mathrm{A}=$ "juice", B = methanol extract 1. C = Expanded UV trace of methanol extract at $520 \mathrm{~nm}, \mathrm{D}=$ full scan search at $\mathrm{m} / \mathrm{z}=1205, \mathrm{E}=$ Mass spectra (280-1500 amu.), $\mathrm{F}=$ full $\mathrm{MS}^{2}$ spectrum of 1205 . Peak annotations refer to Table 2.

dimers of the 4 main black currant anthocyanins, similar to putative anthocyanin dimers linked by carbon-carbon bonds previously described in grape skins $[34,35]$. The proposed dimers eluted from the C18 HPLC column in a predictable order [29] with putative delphinidin-delphinidin dimers before mixed cyanidin-delphinidin dimers and glucose-containing dimers before rutinosides (Table 2). There was also evidence for the presence of CyGlc-CyRut dimer $\left(m / z=1043\right.$ with MS $^{2}=881$ and 573) but it co-eluted with DpGlc.

For example, peaks Ma6 and Ma7 gave $\mathrm{m} / z$ values of 1205 with MS ${ }^{2}$ fragments at 1059 (M - $146=$ rhamnosyl), 897 (M - 308 = rutinoside), $751(\mathrm{M}-454=$ rutinoside + rhamnose $)$ and $589(\mathrm{M}-616=$ rutinoside + rutinoside $)($ Fig. 3D-F). The base $\mathrm{MS}^{2}$ fragment at 589 (actual mass $=588$ ) could be formed by a dimer of cyanidin and delphinidin units $(287+303=590)$ minus two hydrogens suggesting a carbon to carbon bond. Indeed, the $\mathrm{MS}^{2}$ fragmentation pattern of the base $m / z 589$ component fits with previous findings [34, 35] for anthocyanin dimers from grapes. It gave a main fragmentation product at $\mathrm{m} / \mathrm{z}=463$, a neutral loss of $126 \mathrm{Da}$, which could result from heterocyclic ring fission of the C-ring to produce trihydroxybenzene $[34,36]$ from the A-ring of either cyanidin or delphinidin (see Fig. 4). The $\mathrm{MS}^{2}$ products at 303 and 287 suggest breakdown to delphinidin and cyanidin respectively. The more minor fragment at 437 (loss of $152 \mathrm{Da}$ ) could be due to loss of an vinyl alcohol derivative of the B-ring of cyanidin after a retroDiels-Alder (RDA) fission of the C-ring (see Schematic 1; [37-39]. The other fragmentation product at $m / z=419$ (loss of $170 \mathrm{Da}$ ) was $18 \mathrm{Da}$ greater but is more difficult to assign. In addition, the base $\mathrm{MS}^{2}$ fragment at 605 (for the putative delphinidin-delphinidin dimer peaks Ma1 - Ma4) gave a similar fragmentation pattern with 479 (loss of 126, trihydroxybenzene), 435 (loss of 170), 303 (loss of 302, delphinidin) and $m / z=453$ (loss of 152) (results not shown). 


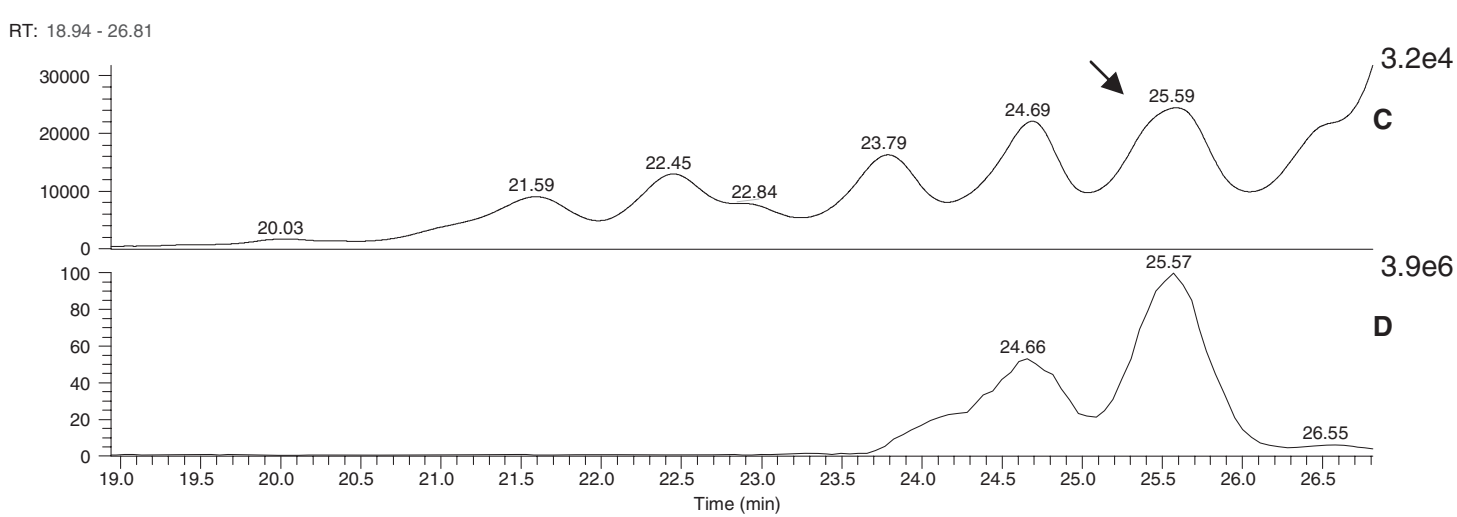

ESI Full ms [80-2000.00]
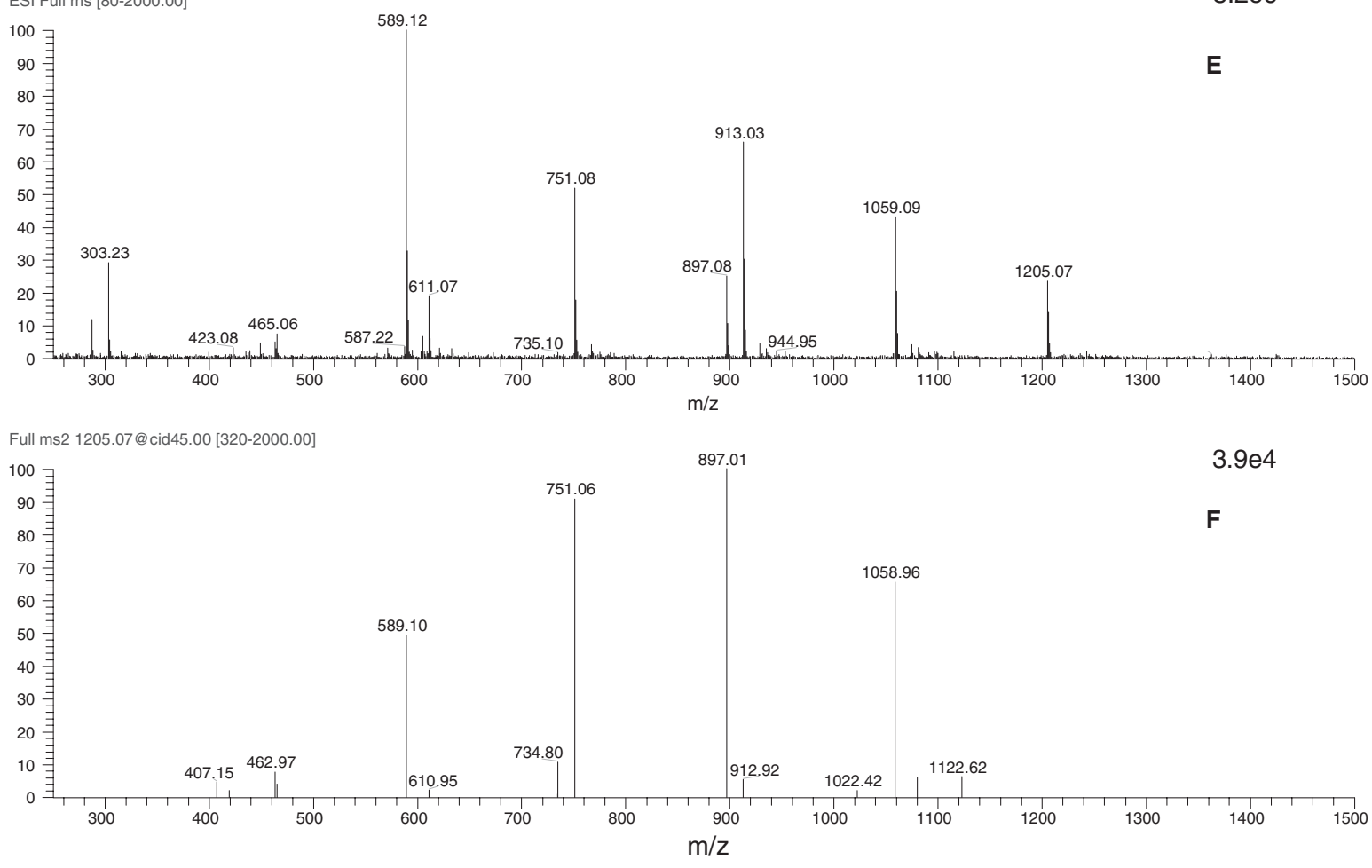

Fig. 3. (Continued)

These dimers were not detected in the juice and water extracts but may be hidden by other more abundant components. The dimers were also detected in methanol extracts obtained using a faster, smaller-scale procedure which was maintained at $4{ }^{\circ} \mathrm{C}$ throughout (results not shown), which suggests these components are not artefacts formed during extraction; a conclusion also reached by Vidal et al. [34]. The appearance of the dimers in the methanol extracts strongly suggests that they are bound to the residues, perhaps arising from the berry skins. Commercial juice production often involves use of pectinolytic and other cell-wall-digesting enzymes [e.g. 26] and it was notable that these anthocyanin dimers were not identified in the ethanol extracts of the industrial pomace. Indeed, these dimers could not be detected in a range of commercially-available black currant juice products from the European Union [40] although these were mostly dilute solutions of juice.

After ingestion of berries, these residue-bound components may be released during gastrointestinal digestion and could engender a slow-release of polyphenols throughout the gut from stomach to the colon [41]. It is intriguing to 
Table 2

Putative identity of anthocyanin-like peaks in black currant extracts

\begin{tabular}{|c|c|c|c|c|c|}
\hline Peak & $\mathrm{T}_{\mathrm{R}}$ & PDA & $m / z[\mathrm{M}+\mathrm{H}]$ & $\mathrm{MS}^{2}$ & Put. ID \\
\hline A1 & 21.36 & 535,285 & 899.1, 591.1, 423.0, 287.2 & 591.1, 423.0, 287.3 & Cy-EGC-Rut \\
\hline A2 & 22.64 & 535 & 915.1, 607.1, 303.1 & $\mathbf{6 0 7 . 1}, 589.1,439.1,303.1$ & Dp-EGC-Rut \\
\hline A3 & 23.65 & 535 & 899.1, 591.1, 423.0, 287.2 & 591.1, 423.0, 287.2 & Cy-EGC-Rut \\
\hline A4 & 29.22 & 525,285 & 465.0, 303.2 & 303.2 & DpGlc \\
\hline A5 & 30.07 & 525,285 & 611.1, 303.2 & $465.0,303.2$ & DpRut \\
\hline A6 & 31.65 & 515,285 & 449.0, 287.3 & 287.3 & CyGlc \\
\hline A7 & 32.57 & 515,285 & 595.1, 287.3 & $449.0,287.3$ & CyRut \\
\hline A8 & 47.83 & $525,320,285$ & 611.1, 303.2 & $464.9, \mathbf{3 0 3 . 2}$ & DpCoumGlc \\
\hline A9 & 50.31 & $520,320,285$ & $\mathbf{5 9 5 . 0}, 287.2$ & $287.2,449.0$ & CyCoumGlc \\
\hline Ma1 & 20.03 & 530,280 & 1075.1, 929.0, 913.0, 767.0, 605.1, 303.2 & $913.0,767.0, \mathbf{6 0 5 . 1}$ & DpGlc-DpRut \\
\hline $\mathrm{Ma} 2$ & 21.59 & 530,280 & 1075.1, 929.0, 913.0, 767.0, 605.1, 303.2 & $913.0,767.0, \mathbf{6 0 5 . 1}$ & DpGlc-DpRut \\
\hline Ma3 & 22.45 & 530,280 & 929.0, 767.1, 605.1, 303.2 & $767.0, \mathbf{6 0 5 . 1}, 303.2$ & DpGlc-DpGlc \\
\hline Ma4 & 22.85 & 530,280 & $\begin{array}{l}\text { 1221.1, 1075.0, 1059.0, 929.1, 913.0, 767.1, } \\
605.1,589.0\end{array}$ & multiple & DpRut-DpRut \\
\hline Ma5 & $\begin{array}{l}23.85 \text { front } \\
23.85 \text { rear }\end{array}$ & 530,280 & $\begin{array}{l}\text { 1075.1, 929.0, 913.0, 767.0, 605.1, } 303.2 \\
\text { 1059.1, 897.1, 751.1, 589.1, 303.2 287.2 }\end{array}$ & $\begin{array}{l}913.0,767.0, \mathbf{6 0 5 . 1} \\
\mathbf{8 9 7 . 1}, 751.1,589.1\end{array}$ & $\begin{array}{l}\text { DpGlc-DpRut } \\
\text { DpGlc-CyRut }\end{array}$ \\
\hline Ma6 & 24.69 & 530,280 & $\begin{array}{l}\text { 1205.1, 1059.0, 913.0, 897.1, 751.1, 611.1, } \\
\text { 589.1, 465.1, 303.2, } 287.2\end{array}$ & 1059.1, 897.0, 751.0, 589.1 & DpRut-CyRut \\
\hline Ma7 & 25.58 & 530,280 & $\begin{array}{l}\text { 1205.1, 1059.0, 913.0, 897.1, 751.1, 611.1, } \\
589.1,465.1,303.2,287.2\end{array}$ & 1059.1, 897.0, 751.0, 589.1 & DpRut-CyRut \\
\hline Ma8 & 25.68 & 520 & 913.1, 751.0, 589.1, 465.1, 303.2, 287.2 & $751.0, \mathbf{5 8 9 . 1}$ & DpGlc-CyGlc \\
\hline Ma9 & 26.53 & 520 & 1059.1, 897.1, 751.1, 589.1, 303.2, 287.2 & $\mathbf{8 9 7 . 1}, 751.1,589.1$ & DpGlc-CyRut \\
\hline
\end{tabular}

All peak numbers refer to Figs. 1 and 3 . $\mathrm{Cy}=$ cyanidin; $\mathrm{Dp}=$ delphinidin; Rut = rutinoside; Glc=glucoside; EGC=epigallocatechin; coum = coumaroyl. All glycosides are assumed to be 3-O-linked (Sandell et al., 2009). Figures in bold represent the main signals.

speculate if these components contribute to the intense pigmentation of black currant and other berry skins, which is a determinant of quality in black currants, and whether their levels differ between different cultivars.

\section{Material and methods}

\subsection{Sample preparation}

Black currants (Ribes nigrum, variety 8982-6 from the James Hutton Institute breeding programme) were grown at Bradenham Hall, Norfolk, UK. They were picked when deemed commercially-ripe and transported frozen to Dundee. As far as possible, every procedure was carried out in the dark or in restricted light. Frozen black currants $(1 \mathrm{~kg})$ were thawed and homogenised in a Waring Blender in five batches using $200 \mathrm{ml}$ distilled water $\left(\mathrm{dH}_{2} \mathrm{O}\right) \mathrm{for}$ $200 \mathrm{~g}$ berries. The resultant juice was filtered twice through 3 layers of muslin which removed particulate matter then filtered through a glass sinter (porosity $2 \mu \mathrm{m}$ ) with the aid of a vacuum pump. The juice was aliquoted and stored frozen. The entire residue from these filtration steps was combined. Portions of the residue ( $200 \mathrm{~g})$ were re-suspended in $400 \mathrm{ml}$ ice-cold $\mathrm{dH}_{2} \mathrm{O}$, homogenized and vacuum-filtered following the same procedure. The first water extract

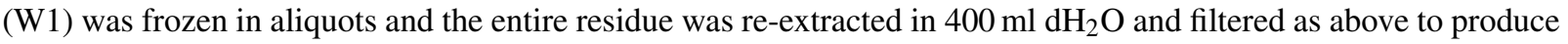
the second water extract (W2). The residue was re-suspended in a small volume of water and placed into dialysis tubing and dialysed against running cold water overnight at $5^{\circ} \mathrm{C}$. The water was discarded afterwards and the residue recovered by centrifugation at $3800 \mathrm{~g}$ for 20 minutes at $5^{\circ} \mathrm{C}$. Finally, after this extensive dialysis, the residue was washed once more with water as described above. This final water wash contained $<10 \mu \mathrm{g}$ GAE/100 mL phenol content. 


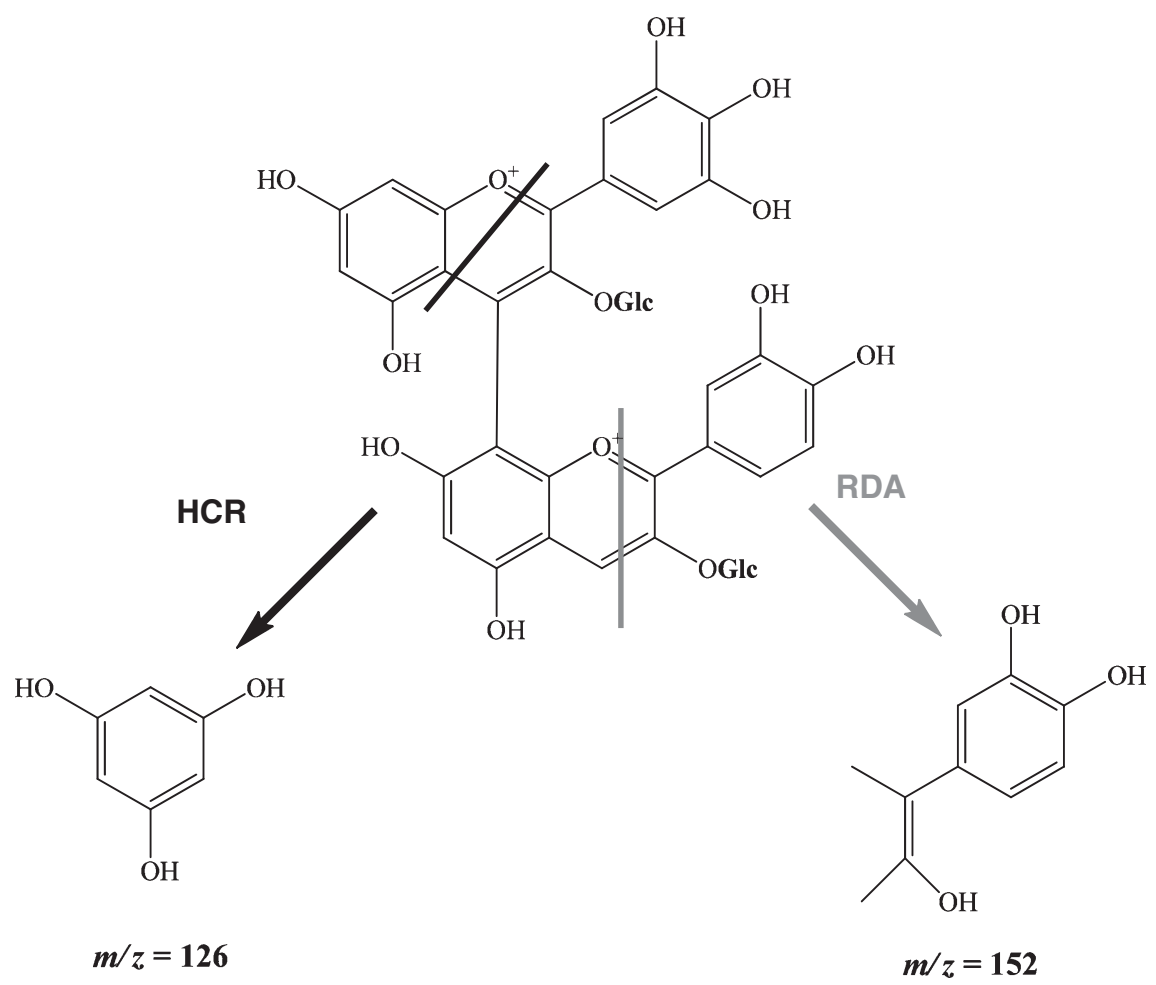

Fig. 4. Putative structure of DpGlc-CyGlc dimer with fragmentation patterns. Possible fragmentation pathways by retro-Diels-Alder rearrangement (RDA) and heterocyclic ring fission (HCR) are shown with potential products.

The water-extracted residue was placed in ice-cold methanol $(400 \mathrm{ml})$ and incubated on a shaker $(100 \mathrm{rpm})$ at $4{ }^{\circ} \mathrm{C}$ for 30 mins in the dark. The first methanol extract (M1) was recovered by centrifugation as above and the supernatant stored in a freezer. This extraction was repeated to produce the second methanol extract (M2). In addition, small amounts of black currants were frozen in liquid nitrogen, freeze-dried then pulverised in a mortar and pestle. The powder $(3 \times 50 \mathrm{mg})$ was extracted in $20 \mathrm{ml}$ ice-cold $\mathrm{dH}_{2} \mathrm{O}$ with vigorous mixing for $10 \mathrm{mins}$ then centrifuged at $5000 \mathrm{~g}$ for $10 \mathrm{~min}$ at $4^{\circ} \mathrm{C}$. The supernatant was decanted and extraction procedure repeated 8 times until the extract was colourless and contained $<10 \mu \mathrm{g}$ GAE/ $100 \mathrm{~mL}$ phenol content. Then the pellet was extracted with $10 \mathrm{ml}$ methanol. All extracts were aliquoted into suitable volumes and stored at $-20^{\circ} \mathrm{C}$. Some aliquots were dried in a speed vac (Thermo Scientific Ltd, Loughborough, U.K.).

Seedless black currant pomace was obtained from New Holland Extraction Ltd (New Holland, Lincolnshire, UK) and was passed through kitchen sieves to remove extraneous material such as twigs etc. After freezing and freeze drying to remove water, the material was ground to pass a $0.5 \mathrm{~mm}$ sieve in a UDY cyclone mill. Samples $(3 \times 25 \mathrm{~g})$ of the pomace were weighed out into $500 \mathrm{ml}$ plastic centrifuge bottles before adding $450 \mathrm{ml} \mathrm{dH}_{2} \mathrm{O}$. The samples were extracted with rotary shaking at $180 \mathrm{rpm}$ under tin foil for $45 \mathrm{~min}$ on an R100 Luckham Rotatest shaker. The bottles were then centrifuged $\left(5000 \times \mathrm{g}, 10 \mathrm{~min}, 4^{\circ} \mathrm{C}\right)$ and the supernatant was retained. After washing with a further 5 volumes of $\mathrm{dH}_{2} \mathrm{O}$, the pellets from the first water extraction were re-extracted in $450 \mathrm{ml}$ of ethanol using the same procedure. After centrifugation $\left(5000 \times \mathrm{g}, 10 \mathrm{~min}, 4^{\circ} \mathrm{C}\right)$, the ethanol extract was obtained.

\subsection{Anthocyanin, phenol and FRAP measurements}

The total anthocyanin concentration was estimated by a pH differential absorbance method [7]. The absorbance value was related to anthocyanin content using the molar extinction coefficient calculated for cyanidin-3-O-glucoside 
(purchased from ExtraSynthese Ltd, Genay, France). Phenol content was measured using a modified Folin-Ciocalteau method [7] using a standard curve of gallic acid.

The ferric reducing ability of plasma (FRAP) assay was employed as a measure of antioxidant capacity and was carried out according to the method outlined previously [7]. Samples were dried to a fixed amount of phenols (e.g. $250 \mu \mathrm{g}$ gallic acid equivalents [GAE]) using a Speed-Vac (Thermo Scientific).

\subsection{Liquid chromatography-mass spectrometric analysis}

Extracts containing $20 \mu \mathrm{g}$ phenols (GAE) were analysed on an LCQ-Deca system, comprising Surveyor autosampler, pump and photodiode array detector (PDA) and a ThermoFinnigan ion-trap mass spectrometer following previous methodology (28). The PDA scanned 3 discrete channels at 280, 365 and $520 \mathrm{~nm}$. The samples were applied to a C18 column (Synergi Hydro C18 with polar endcapping, $4.6 \times 150 \mathrm{~mm}$, Phenomenex Ltd) and eluted using a gradient of 5-40\% acetonitrile ( $0.1 \%$ formic acid) over $60 \mathrm{~min}$ at a rate of $400 \mu \mathrm{l} / \mathrm{min}$. The LCQ-Deca LC-MS was fitted with an ESI (electrospray ionisation) interface and analysed the samples in positive and negative ion mode. There were two scan events; full scan analysis followed by data-dependent MS/MS of the most intense ions using collision energies (source voltage) of $45 \%$. The capillary temp was set at $250^{\circ} \mathrm{C}$, with sheath gas at 60 psi and auxiliary gas at 15 psi. The levels of anthocyanins were estimated from the MS peak areas provided by searching the MS data at their respective $m / z[\mathrm{M}+\mathrm{H}]$ values. Areas were averages of triplicate injections.

\section{Acknowledgments}

We acknowledge funding from the Rural and Environment Research Analysis Directorate, Scottish Government. This work is aligned to EU projects CLIMAFRUIT (www.climafruit.com/) and BRAINHEALTHFOOD (http://www.uku.fi/brainhealthfood/). We thank the University of Applied Sciences in Mannheim for allowing Karin Juedtz to carry out her project at JHI. We thank the University of Dundee for allowing Nicola Aberdein to carry out her Honours project at JHI. We thank Dr Rex Brennan (JHI) for the supply of the black currant breeding line used in this study. We are grateful to New Holland Extraction Ltd for the supply of black currant pomace. 


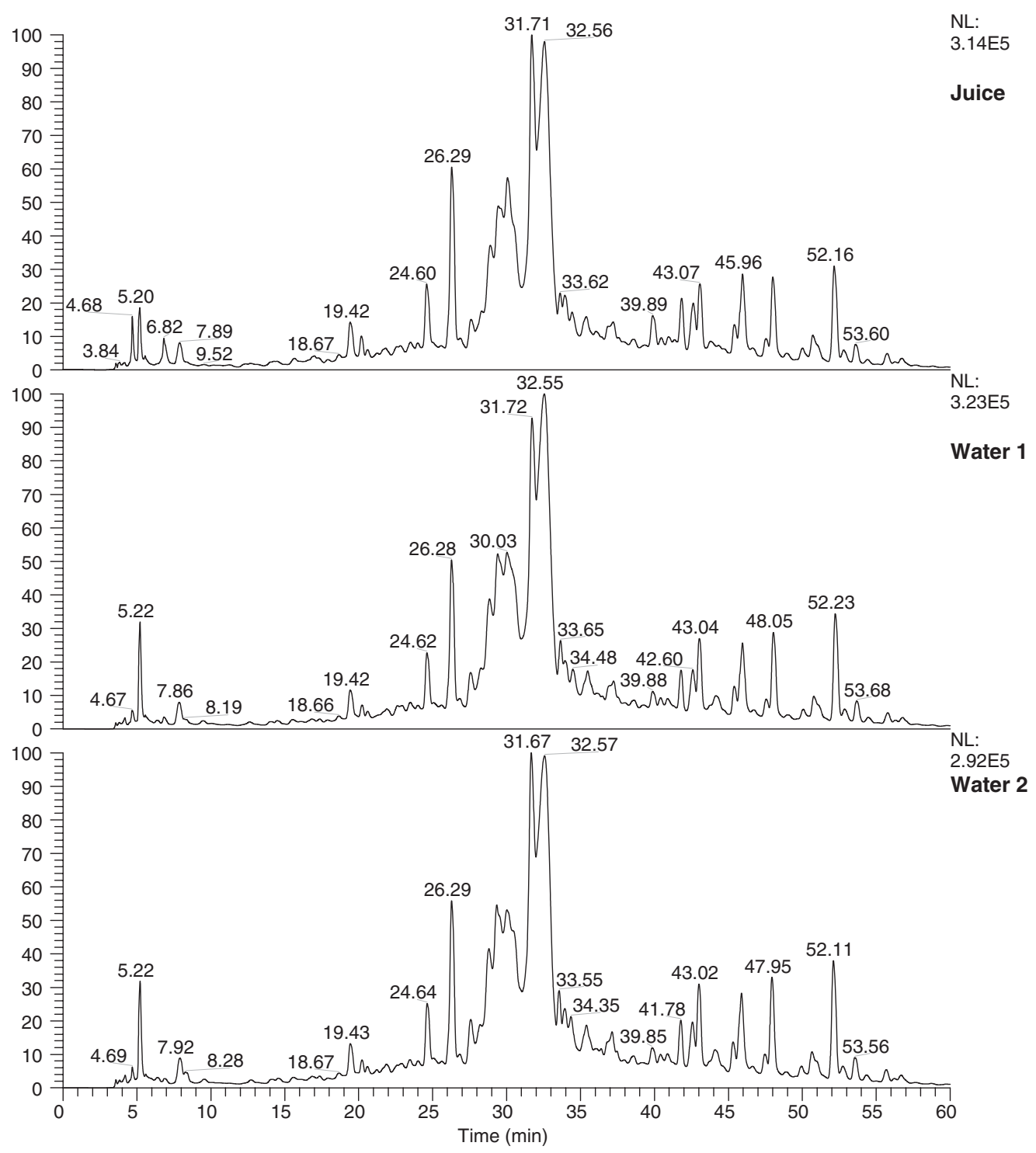

Supplementary Figure 1. Profiles of juice and water extracts. PDA profiles are shown. The full scale deflections are given in each panel.

\section{References}

[1] Brennan RM. Currants and gooseberries (Ribes spp.) In: Breeding of Temperate Fruit Crops, Temperate Fruit Crop Breeding: Germplasm to Genomics. (J.F. Hancock Ed.). London: Springer; 2008, pp. 177-96.

[2] Hackett CA, Russell J, Jorgensen L, Gordon SL, Brennan RM. Multi-environment QTL mapping in blackcurrant (Ribes nigrum L.) using mixed models. Theoretical and Applied Genetics. 2002;121:1483-8.

[3] Machiex JFA, Fleuriet A, Billot, J. Fruit phenolics. Florida, USA: CRC Press; 1990.

[4] Clifford MN. Anthocyanins - nature, occurrence and dietary burden. Journal of the Science of Food and Agriculture. 2000;80:1063-72.

[5] Määttä-Riihinen KR, Kamal-Eldin A, Matiila PH, Gonzalez-Paramas AM, Törrönen R. Distribution and contents of phenolic compounds in eighteen Scandinavian berry species. Journal of Agricultural and Food Chemistry. 2004;52:4477-86.

[6] Sandell M, Laaksonen O, Järvinen R, Rostiala N, Pohjanheimo T, Tiitinen K, Kallio H. Orosensory profiles and chemical composition of black currant (Ribes nigrum) juice and fractions of press residue. Journal of Agricultural and Food Chemistry. 2009;57:3718-28. 
[7] Deighton N, Brennan R, Finn C, Davies HV. Antioxidant properties of domesticated and wild Rubus species. Journal of the Science of Food and Agriculture. 2000;80:1307-13.

[8] Kahkonen MP, Heinamaki J, Ollilainen V, Heinonen M. Berry anthocyanins: Isolation, identification and antioxidant properties. Journal of Agricultural and Food Chemistry. 2003;83:1403-11.

[9] Toufektsian MC, De Lorgeril M, Nagy N, Salen P, Donati MB, Giordano L, Mock HP, Peterek S, Matros A, Petroni K, Pilu R, Rotilio D, Tonelli C, De Leiris J, Boucher F, Martin C. Chronic dietary intake of plant-derived anthocyanins protects the rat heart against ischemiareperfusion injury. Journal of Nutrition. 2008;138:747-52.

[10] Thomasset S, Teller N, Cai H, Marko D, Berry DP, Steward WP, Gescher AJ. Do anthocyanins and anthocyanidins, cancer chemopreventive pigments in the diet, merit development as potential drugs? Cancer Chemotherapy and Pharmacology. 2009;64:201-11.

[11] Tsuda T. Regulation of adipocyte function by anthocyanins: Possibility of preventing the metabolic syndrome. Journal of Agricultural and Food Chemistry. 2008;56:642-6.

[12] Andres-Lacueva C, Shukitt-Hale B, Galli RL, Jauregui O, Lamuela-Raventos RM, Joseph JA. Anthocyanins in aged blueberry-fed rats are found centrally and may enhance memory. Nutrition and Neuroscience. 2005;8:111-20.

[13] Matsumoto H, Nakamura Y, Tachibanaki S, Kawamura S, Hirayama M. Stimulatory effect of cyanidin 3-glycosides on the regeneration of rhodopsin. Journal of Agricultural and Food Chemistry. 2003;51:3560-3.

[14] Jayaprakasam B, Olson LK, Schutzki RE, Tai M-H, Nair MG. Amelioration of obesity and glucose intolerance in high-fat-fed C57BL/6 mice by anthocyanins and ursolic acid in cornelian cherry (Cornus mas). Journal of Agricultural and Food Chemistry. 2006;54:243-8.

[15] FAO statistics, 2007; http://faostat.fao.org/

[16] Slimestad R, Solheim, H. Anthocyanins from black currants (Ribes nigrum L.). Journal of Agricultural and Food Chemistry. 2002;50: 3228-31.

[17] Landbo AK, Meyer AS. Enzyme-assisted extraction of antioxidative phenols from black currant juice press residues (Ribes nigrum). Journal of Agricultural and Food Chemistry. 2001;49:3169-77.

[18] Lu Y, Foo LY. Polyphenolic constituents of blackcurrant seed residue. Food Chemistry. 2003;80:71-6.

[19] Kapasakalidis PG, Rastall RA, Gordon MH. Extraction of polyphenols from processed black currant (Ribes nigrum L.) residues. Journal of Agricultural and Food Chemistry. 2006;54:4016-21.

[20] Karjalainen R. Anttonen M, Saviranta N, Stewart D, McDougall GJ, Hilz H, Mattila P, Torronen R, Hanke MV, Dunemann F, Flachowsky H. A review on bioactive compounds in black currants (Ribes nigrum L.) and their potential health-promoting properties. Acta Horticulturae. 2009;839:301-307.

[21] Sójka M, Król B. Composition of industrial seedless black currant pomace. European Food Research and Technology. 2009;228:597-605.

[22] Stewart D, Deighton N, Davies, HV. Contribution of cell-wall bound components to the antioxidant capacity of soft fruit. Proceedings of COST Action 916 Meeting: Bioactive compounds in plant foods - Health Effects and Perspectives for the Food Industry, 12-14th October 2000, Tenerife, Spain.

[23] Wu X, Gu L, Prior RL, McKay S. Characterization of anthocyanins and proanthocyanidins in some cultivars of Ribes, Aronia, and Sambucus and their antioxidant capacity. Journal of Agricultural and Food Chemistry. 2004;52:7846-56.

[24] Määttä K, Kamal-Eldin A, Törrönen R. Phenolic compounds in berries of black, red, green, and white currants (Ribes sp.). Antioxidants and Redox Signaling. 2001;3:981-93.

[25] Määttä K, Kamal-Eldin A, Törrönen R. High-performance liquid chromatography (HPLC) analysis of phenolic compounds in berries with diode array and electrospray ionization mass spectrometric (MS) detection: Ribes species. Journal of Agricultural and Food Chemistry. 2003;51:6736-44.

[26] Koponen JM, Happonen AM, Auriola S, Kontkanen H, Buchert J, Poutanen KS, Törrönen AR. Characterization and fate of black currant and bilberry flavonols in enzyme-aided processing. Journal of Agricultural and Food Chemistry. 2008;56:3136-44.

[27] Anttonen MJ, Karjalainen RO. High-performance liquid chromatography analysis of black currant (Ribes nigrum L.) fruit phenolics grown either conventionally or organically. Journal of Agricultural and Food Chemistry. 2006;54:7530-8.

[28] McDougall GJ, Gordon S, Brennan R, Stewart D. Anthocyanin-flavanol condensation products from black currant (Ribes nigrum L.). Journal of Agricultural and Food Chemistry. 2005;53:7878-85.

[29] Djilas S, Canadanovic-Brunet J, Cetkovic G. By-products of fruits processing as a source of phytochemicals. Chemical Industry and Chemical Engineering Quarterly. 2009;15:191-202.

[30] Sójka M, Guyo S, Kołodziejczyk K, Król B, Baron A. Composition and properties of purified phenolics preparations obtained from an extract of industrial blackcurrant (Ribes nigrum L.) pomace. Journal of Horticultural Science \& Biotechnology. 2009; ISAFRUIT Special Issue: $100-106$

[31] Seabra IJ, Braga MEM, Batista MTP, De Sousa HC. Fractioned high pressure extraction of anthocyanins from elderberry (Sambucus nigra L.) pomace. Food and Bioprocess Technology. 2010;3:674-83.

[32] Laroze E, Diaz-Reinoso B, Moure A, Zuniga ME, Dominguez H. Extraction of antioxidants from several berries pressing wastes using conventional and supercritical solvents. European Food Research and Technology. 2010;231:669-77.

[33] Saura-Calixto F. Dietary fiber as a carrier of dietary antioxidants: An essential physiological function. Journal of Agricultural and Food Chemistry. 2011;59:43-9. 
[34] Vidal S, Meudec E, Cheynier V, Skouroumounis G, Hayasaka Y. Mass spectrometric evidence for the existence of oligomeric anthocyanins in grape skins. Journal of Agricultural and Food Chemistry. 2004;52:7144-51.

[35] Pati S, Liberatore MT, Gambacorta G, Antonacci D, La Notte E. Rapid screening for anthocyanins and anthocyanin dimers in crude grape extracts by high performance liquid chromatography coupled with diode array detection and tandem mass spectrometry. Journal of Chromatography A. 2009;1216:3864-68.

[36] Gu L, Kelm MA, Hammerstone JF, Zhang Z, Beecher G, Holden J, Haytowitz D, Prior RL. Liquid chromatographic/electrospray ionization mass spectrometric studies of proanthocyanidins in foods. Journal of Mass Spectrometry. 2003;38:1272-80.

[37] Friedrich W, Eberhardt A, Galensa R. Investigation of proanthocyanidins by HPLC with electrospray ionization mass spectroscopy. European Food Research and Technology. 2000;211:56-64.

[38] Salas E, Atanasova C, Poncet-Legrand E, Meudec, JP, Cheynier V. Demonstration of the occurrence of flavanol anthocyanin adducts in wine and in model solutions. Analytica Chimica Acta. 2004;523:325-32.

[39] Sun B, Barradas T, Leandro C, Santos C, Spranger I. Formation of new stable pigments from condensation reaction between malvidin 3-glucoside and (-)-epicatechin mediated by acetaldehyde: Effect of tartaric acid concentration. Food Chemistry. 2008;110:344-51.

[40] Mattila PH, Hellstrom J, McDougall GJ, Dobson G, Pihlava J-M, Tiirikka T, Stewart D, Karjalainen R. Polyphenol and vitamin C contents in European commercial blackcurrant juice products. Food Chemistry. 2011;127:1216-23.

[41] McDougall GJ, Dobson P, Shpiro F, Fyffe S, Smith P, Stewart D. Assessing bioavailability of soft fruit polyphenols in vitro. Acta Horiculturae. 2007;744:135-48. 